\title{
Multislice Bilgisayarlı Tomografi ile Median Arkuat Ligament Sendromu Tanısi: Olgu sunumu
}

\author{
Hanifi Bayaroğulları ${ }^{1}$, Ramazan Davran¹, Ahmet Aslan², İnan Korkmaz', \\ Rasim Yanmaz ${ }^{1}$, Muhyittin Temiz ${ }^{2}$ Ali BalCl ${ }^{1}$ \\ Mustafa Kemal Üniversitesi Tıp Fakültesi ${ }^{1}$ Radyodiagnostik Anabilim Dall, ${ }^{2}$ Genel Cerrahi Anabilim Dall, Antakya
}

\begin{abstract}
ÖZET
Multislice bilgisayarlı tomografi ile median arkuat ligament sendromu tanısı: Olgu sunumu

Median arkuat ligament sendromu, median arkuat ligamentin çöliak arter köküne basısı sonucu oluşur ve kendini genellikle postprandial ağıı ile belli eder. Basıya bağı, özelikle ekspiryumda daha belirgin darlık oluşur. Darlığa bağı̆ mezenterik iskemi ve gastro-intestinal sisteme yetersiz kan akımı olması nedeniyle sendroma ait karakteristik klinik bulgular görülür. Biz kliniğimize gelen ve multislice bilgisayarlı tomografi ile tanısı konan hastayı sunuyoruz.
\end{abstract}

Anahtar kelimeler: Median arkuat ligament, çölyak arter, multislice bilgisayarlı tomografi

\begin{abstract}
Median arcuate ligament syndrome diagnosed with multisliced computerized tomography: A case report Median arcuate ligament syndrome occurs when median arcuate ligament pressures the root of the celiac artery and generally it reveals itself with the post-prandial pain. Because of the pressure there will be a significant tightness especially while expirium. Mesenteric ischaemia and low blood flow to gastro-intestinal system occurs related to the tightness and because of these we see the characteristic clinical symptoms of the syndrome. We present the patient whom we diagnosed with multislicde computerized tomograpy. Key words: Median arcuaet ligament, celiac artery, multisliced computerized tomograpy
\end{abstract}

Bakırköy Tıp Dergisi 2012;8:145-147

GíRiş

$\mathrm{M}$ edian arkuat ligament sendromu (MALS), çöliak arterin aortadan hemen orijin aldığı proksimal kesiminde, diafragmanın median arkuat ligamenti tarafindan kompresyonu sonucu gastrointestinal sistemdeki iskemi neticesi gelişir. En önemli belirtisi postprandial karın ağrısıdır. Çöliak arterdeki darlık ve bazen oklüzyon, superior mezenterik arterden, özellikle gastroduodenal dalından kaynaklanan kollateral akım ile kompanse edilir. Biz olgumuzda median arkuat ligament sendromunda multislice bilgisayarlı tomografi (MDBT) bulgularını gösterdik.

Yazışma adresi / Address reprint requests to: Dr. Ahmet Aslan Mustafa Kemal Üniversitesi, Tıp Fakültesi, Genel Cerrahi AD, Antakya Telefon / Phone: +90-532-662-1100

Elektronik posta adresi / E-mail address: drahmetaslan@yahoo.com Geliş tarihi / Date of receipt: 31 Aralık 2010 / December 31, 2010 Kabul tarihi / Date of acceptance: 15 Şubat 2012 / February 15, 2012

\section{OLGU SUNUMU}

Altmış altı yaşında bayan hasta şiddetli karın ağrısı ve karaciğer enzim yüksekliği nedeniyle, MKÜ Tıp Fakültesi Hastanesi Enfeksiyon hastalıkları kliniğine hepatit tanısı ile yatırıldı. Hastanın özgeçmişinde, beyin tümörü nedeniyle operasyon öyküsü vardı. Hastaya rutin ultrasonografi (US), abdominal BT ve kolon grafisi çekildi. Kolon grafisinde haustralarda düzleşme izlendi. US ve abdominal BT'de belirgin patoloji saptanmadı. Karın ağrısının sürmesi üzerine mezenterik iskemi açısından abdominal aort ve dallarının değerlendirilmesi için BT anjiografi planlandı. Tetkik 64 kesit Toshiba cihazı ile yapıldı (Toshiba Aquilon TSX-101A). 100ml, 400mg/ml non-iyonik kontrast madde $5 \mathrm{~mm} / \mathrm{sn}$ hızla verildikten sonra görüntüler elde edildi. BT protokolünde; kesit kalınlığı $5 \mathrm{~mm}$, pitch 0.775 , rotasyon hızı 0.5 per, gecikme zamanı 18-20sn olarak belirlendi. İşlem bittikten sonra görüntüler iş istasyonuna aktarıldı. Bizim olgumuzda BT angiografik incelemede çöliak arterde MAL basısı sonucu çengel şekline darlık izlenmektedir 

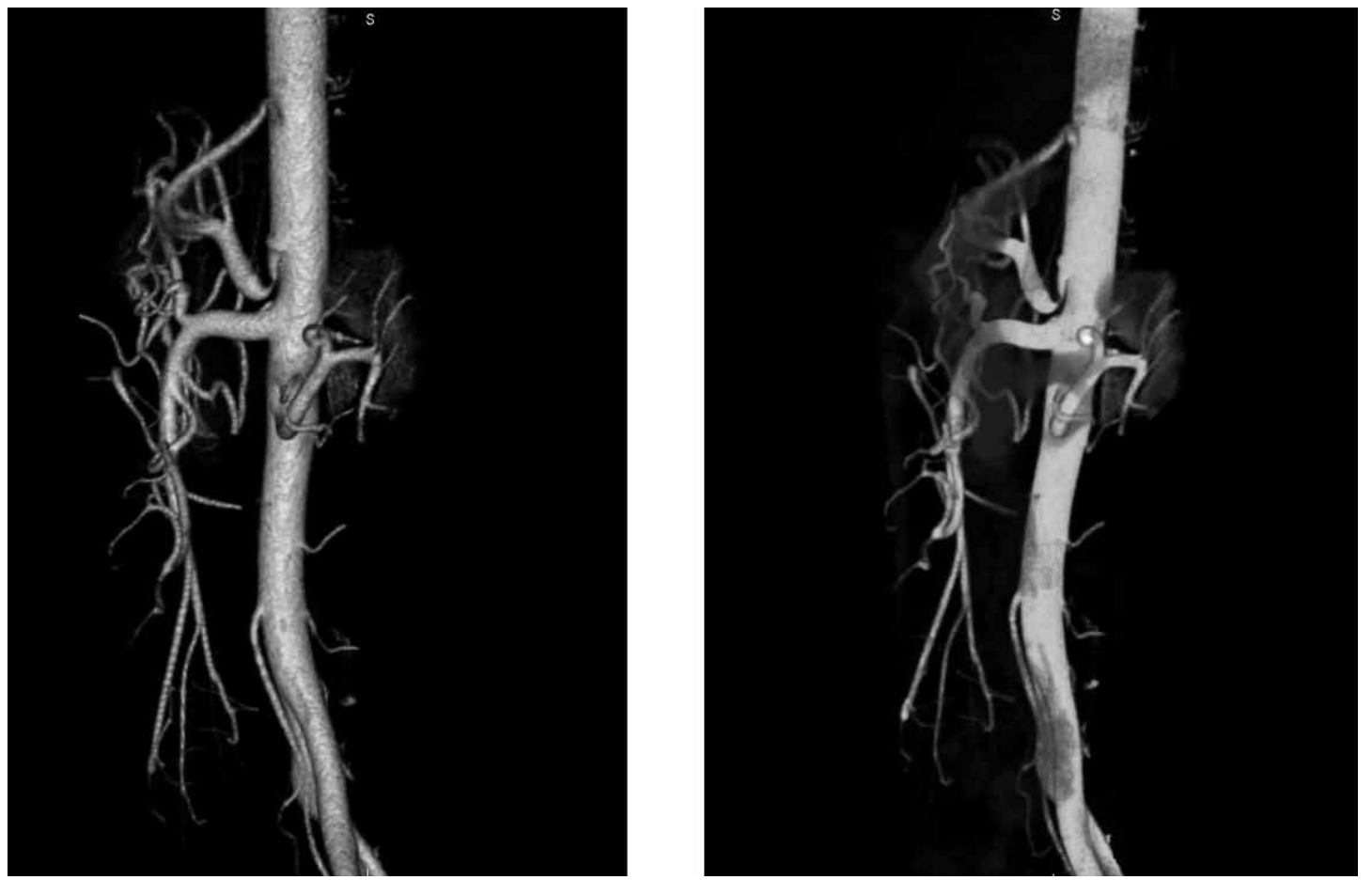

Şekil 1a-b: MDBT 3D ve MIP angiografide çöliak arter proksimalinde çengel şeklinde MAL basısı sonucu daralma
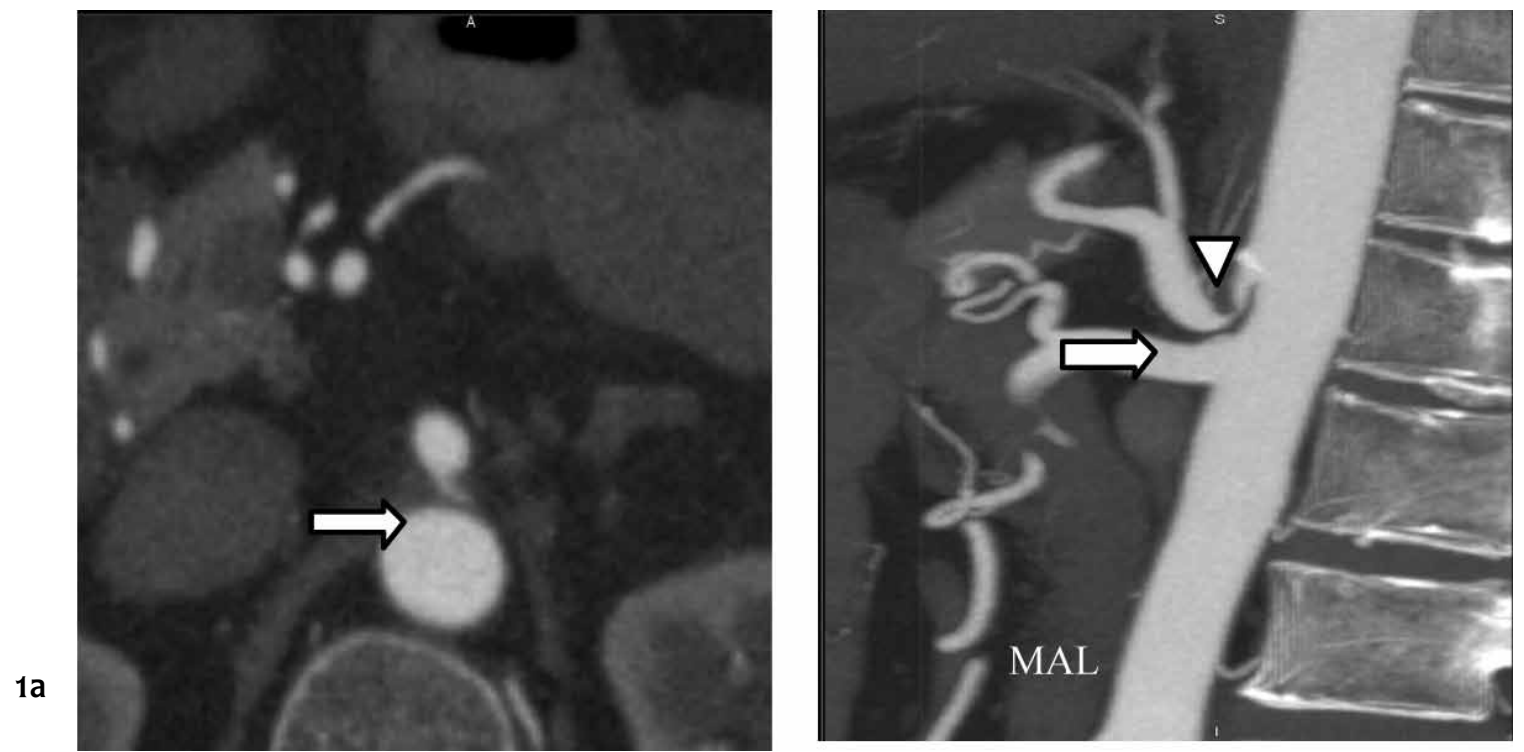

Şekil 2a-b: aksiel ve sagittal alınan multiplanar reformat görüntüde MAL ve çöliak arterde darlık (uzun ok), arter proksimalinde kalsifiye plak izlenmektedir (ok başı).

(Şekil 1). Aksiel ve sagittal planda alınan kesitlerde MAL görüntülenmektedir (Şekil 2 a-b). Konvansiyonel anjiografide lateral görüntülerde darlık izlenmekle beraber, MAL gibi eksternal bası yapan nedenler MDBT ile görüntülenmektedir. Ayrıca olgumuzda çöliak arterin aortadan tam ayrım bölgesinde kalsifiye plak da MDBT ile gösterilebilmektedir (Şekil 2b).

\section{TARTIŞMA}

MAL sendromu, median arkuat ligamentin çöliak arter proksimaline basısı sonucu oluşan nadir bir vasküler patolojidir. Toplumda 100 000'de 2 oranında izlenir (1). Ligament, lomber spinal kolonun her iki tarafında yer alan diafragmatik krusları birleştirir. Abdominal aortanın 
ilk dalı olan çöliak trunkus, bu ligamentöz arkın hemen altından kaynaklanır. Artere olan kompresyonun derecesi diafragmanın pozisyonuna göre değişir. Kompresyonun derecesi derin ekspiryum da en üst seviyeye çıkar. Bazen damardaki bu bası tam obstrüksiyona yol açar. Mesenterik iskemi sonucu, postparandial karın ağrısı, bulantı, kusma ve kilo kaybı gibi klinik bulgular görülür. Hastaların muayenesinde, özellikle ekspiryumda belirginleşen, epigastrik bölgedeki üfürüm önemli bir klinik bulgu olarak karşımıza çıkar. Aortik anevrizma ve retroperitoneal fibroz da az da olsa benzer şikayetlere neden olabilir (2).

Klinik bulguların oluşumunda iki ana teori öne sürülmüştür. İlk teoride çöliak arter kompresyonuna bağlı mezenterik iskemidir. íkinci teori ise çöliak ganglion ve pleksus kompresyonuna bağlı nörojenik stimulasyon olarak ileri sürülmüştür (3-5).

MALS teşhisinde renkli Doppler US, konvansiyonel anjiografi, MRG ve MDBT kullanılır $(3,6,7)$. Renkli doppler MALS tanısınde yüksek sensitiviteye sahip olup tanı

\section{KAYNAKLAR}

1. Foertsch $\mathrm{T}$, Koch $\mathrm{A}$, Singer $\mathrm{H}$, Lang W. Celiac trunk compression syndrome requiring surgery in 3 adolescent patients. J Pediatr Surg 2007; 42: 709-713.

2. Marcoccia A, Zippi M, Bruni A, et al. Chronic abdominal pain associated with intermittent compression of the celiac artery. Minerva Gastroenterol Dietol 2007; 53: 209-213.

3. Cina CS, Safar H. Successful treatment of recurrent celiac axis compression syndrome. A case report. Panminerva Med 2002; 44: 69-72.

4. Bech FR. Celiac artery compression syndromes. Surg Clin North Am 1997; 77: 409-424.

5. Tribble CG, Harman PK, Mentzer RM. Celiac artery compression syndrome. Report of a case and rewiev of current opinion. Vasc Surg 1986; 20: 120-129. amaçlı kullanılabilir (8).

Konvansiyonel anjiografi, özellikle lateral pozisyonda alınan görüntülerde lezyonu ve kollateral oluşumları görüntülemede yeterli olsa da, lateral alınmayan görüntülerde lezyonu gösterememekte, MAL'i direkt görüntülemede yetersiz kalmaktadır. MRG'de inspiryum ve ekspiryumda alınan görüntülerde, çöliak arterdeki patolojiyi gösterebilmektedir.

MDBT'lerin kullanıma girmesi, hızl, ince kesit, multiplanar reformat ve 3B angiografik görüntüler alabilmesinden dolayı anjiografik görüntüler kolaylıkla elde edilmektedir. MDBT ile sadece stenotik segment gösterilmemekte, MAL ve çevre yumuşak dokular da direk gösterilmektedir. Olgumuzda da darlık ve darlığa yol açan MAL ile çöliak arter proksimalinde kalsifiye plak formasyonu gösterilmiştir. MDBT ile kollateral oluşumlar ve darlığa bağl hemodinamik değişikliklerde gösterilebilmektedir (7-9).

MDBT, MALS tanısında minimal invaziv ve yararlı bir yöntem olmakla birlikte invaziv anjiografik tetkiklerin alternatifi olarak kullanılabilir.

6. Wolfman D, Bluth El, Sossaman J. Median arcuate ligament syndrome. J Ultrasound Med 2003; 22: 1377-1380.

7. Kopecky KK, Stine SB, Dalsing MC, Gottlieb K. Median arcuate ligament syndrome with multivessel involvement: diagnosis with spiral CT angiography. Abdominal Imaging 1997; 22: 318-320.

8. Scholbach T. Celiac artery compression syndrome in children, adolescents, and young adults: clinical and color duplex sonographic features in a series of 59 cases. J Ultrasound Med 2006; 25: 299-305.

9. Horton KM, Talamini MA, Fishman EK. Median arcuate ligament syndrome: evaluation with CT angiography. Radiographics 2005; 25 : 1177-1182. 